Casal, P., Castro-Jiménez, J., Pizarro, M., Katsogyiannis, A., Dachs, J (2018) Seasonal soil/snow-air exchange of semivolatile organic pollutants at a coastal arctic site (Troms $\left.\varnothing, 69^{\circ} \mathrm{N}\right)$. Science of the Total Environment 636, 1109-1116. https://doi.org/10.1016/i.scitotenv.2018.04.330

Seasonal soil/snow-air exchange of semivolatile organic pollutants at a coastal arctic site (Tromsø, $69^{\circ} \mathrm{N}$ )

Paulo Casal ${ }^{\mathrm{a}}$, Javier Castro-Jiménez ${ }^{\mathrm{a}, \mathrm{b}}$, Mariana Pizarro ${ }^{\mathrm{a}}$, Athanasios Katsoyiannis ${ }^{\mathrm{c}}$, Jordi Dachs ${ }^{\mathrm{a}, *}$

"Department of Emironmental Chemisty (IDAEA CSMC), Barcabna, Catdurya, Spain

- Aix Marseille Univ, Univerity \& Toulon CNBS IBD, MD UM 110, Marxille, France

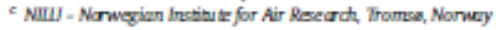

H I G H L I G H T S

- Soil/snow-a ir exchange was evaluated at Tromse for 98 semi-volatile organic pollutants.

- PCBs and HCHs gas-phase concentrations showed a temperature dependent seasona lity.

- Fugadty in air was correla ted with fugacity in soil/snow for PAHs, PCBs and oCps

- Netvol ailization of PAHs and HCBs dur ing the warmer months

- PCBs and HCHs in air and soil/snow were dose to equilibrium.

\section{A RTICLE IN FO}

\section{Antide history:}

Recrived 20 Febru 12 y 2018

Received in revised form 3 April 2018

Accep ed 24 April 2018

Availthle online $x 000$

Ediar: D. Barcelo

\section{Kegurads:}

Arctic

Orgaric pollutarts

Air-soil exchange

PCB

PAH
GRAPHICALABSTRACT

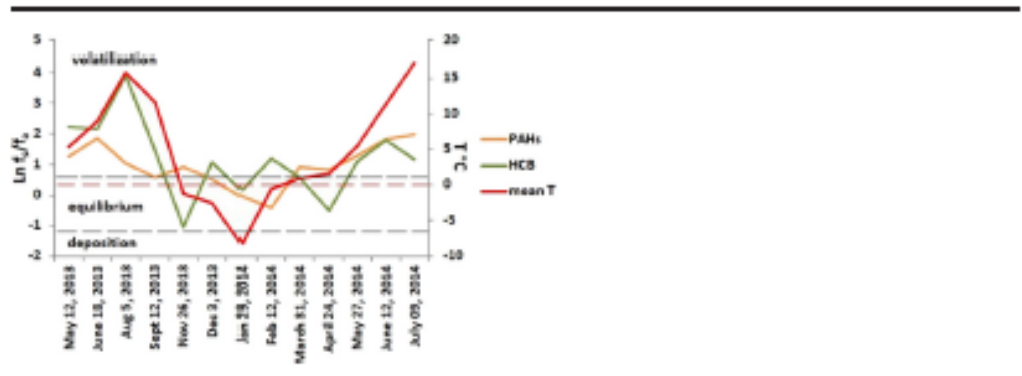

A B S T R A C T

Soiks a re a major reservoir of semivolatile organic pollutants such as polychlorinated biphenyls (PCBs) and polycyclic aroma ic hydrocarbons (PAHs), and exert a control on their atmospheric occurrence. We present here an assersment of the atmospheric occurrence and seasonality of soil/snow-air partitioning and exchange of PCBs, PAHs, hexachlorobenzene (HCB), and hexachlorocyclohexanes (HCHs) in the arcticcity Tromse, northerm Norway. The fugacites of the organic poll utants in soils and snow were determined using a soil fugacity sampler by equilibrating the air concentrations with those in the surface soil snow. The concentrations in soils did not show a significantseasonality. Corversely, the ambient airconcentrations and the soil (or snow) fugadity showed a clear seasonality for PCBs, $\mathrm{HCH}, \mathrm{HCB}$ and some PAHs, related to temperature. Fugadies in soil/snow were correlated with those in the ambient gas phase, suggesting a dose seasonal air-soil/snow coupling Generally, there was a net deposition or close to equilibrium conditions during the winter, which contrasts with the net volatilization observed dur ing the warmer periods. The chemicals with lower octanol-air partition coeffidents showed a larger tendency for be ing volatilized and thus remobilized from this coastal arctic environment Corversely, the more hydrophobic compounds were clase to air-soil/snow equilibrium or showed a net deposition.

Q 2018 Esevier BV. All rights reserved.

\section{Introduction}

Semi-volatile organic compounds (SVOCs), such as organochlorine pesticides (OCPs), polycyclic aromatic hydrocarbons (PAHs) and

\footnotetext{
- Corresponding atthor.

E-mail aldrex: jordi dacts eidueacsices (1. Dxhts)
}

polychlorinated biphenyls (PCBs), are ubiquitous pollutants of glo bal environmental concern (UNEP, 2001). The effectiveness of important global regulations aimed to control emissions of some legacy SVOCs, such as the Stockholm Convention on persistent organic pollutants (POPs), has led to a decline of their atmospheric concentrations in many cases (UNEP, 2001; Nizzetto et al., 2010; Dvorská et al., 2009). However, the long rangs atmospheric transport (LRAT) potential and 
slow degradability of some of these compounds sustain their occurrence, from urban and industrial areas to background and remote environments (Gal bán-Malagón et al_, 2013a 2013b; Cabrerizo et al, 2013b, 2014, 2016)

Soils are a major reservoir and sink for hydrophobic SVOCs due to their high affinity to organic matter (Dalla Valle et al., 2005). Aside from direct inputs, the occurrence of SVOCs in soils and the atmosphere depends al so on the mechanisms of atmospheric deposition and volatilization. The net direction of the soil-air and snow-air diffisive exchange (i.e. transport of gas phase SVOCs at the soil/snow-air interface) is driven by environmental factors, mainly temperature and the soil organic matter (SOM) (Cabrerizo et al., 2011a, 201 1b, 2013a, 2013b, 2014). Soil coverage (i.e. soil with grass versus snow) can also affect SVOCs air-surface partitioning. Soils can have higher amounts of organic matter, while snow has a large specific surface area. The study of the direction of soil-air diffusive exchange for a specific chemical can be approached by measuring the chemical's fugacity in air and soil. Fugacity describes the escaping tendency of a chemical from a specific medium, such as soil, snow or air (Mackay and Paterson, 1981). The previously described soil fugacity sampler (Cabrerizo et al., 2009) allows its direct measurement under field conditions, and thus the soil// snow fugacity does not need to be estimated from $\mathrm{POP}$ concentrations in soils and/or models. Previous fugacity based field studies of soil-air exchange of POPs focused on temperate European background sites (Cabrerizo et al, 2011a, 2011b, 2011c, 2013a; Degrendele et aL, 2016), and polar regions in the southern hemisphere (Antartica) (Cabrerizo et al., 2013b, 2014). In a recent study, diurnal variations in air and soil fugacity were characterized at a background region of central Europe (Degrendele et al, 2016), and tied to temperature changes among other factors. However, the seasonal effects of temperature and other climatic/biogeochemical variables on the soil-air diffusive exchange have only been partially explored in regions from the northern lberian Peninsula (Cabrerizo et al, 2011 a, 2011 b, 2011c), but not in other climatic regions, and few or no data exist in polar regions from the northern hemisphere. The soils from high latitude regions can have a high reserve capacity for POPs (Dalla Valle et aL, 2005), and are important for the global distribution of POPs and to study the potential impact of these toxic chemicals in these fragile ecosystems.

The main objective of this study was to investigate, for the first time, the seascnality of the air-soil/snow exchange of PCBs, OCPs and PAHs in an arctic region (Troms $69^{\circ} \mathrm{N}$ ) where soils are frozen, seasonally covered with snow, and with a high temperature range $\left(25^{\circ} \mathrm{C}\right)$ between summer and winter. In order to achieve this objective, a 14-month sampling campaign using a fugacity sampler was performed.

\section{Materials and methods}

\subsection{Sampling}

All samples were collected in a carefully selected urban site in the main island of Tromse (Tromsoya), Norway (N $69^{\circ} 38^{\prime} 35.8^{*} \mathrm{E} 18^{\circ} 56^{\prime}$ 54.5 ). A fugacity sampler (Cabrerizo et al., 2009) was deployed for 5 or 6 days in 14 sampling events between May 2013 and July 2014 . This sampler allows for the simultaneous collection of an ambient air sample and a sample of air equilibrated in-situ with the soil/snow surface for each sampling event. The latter is a measure of the fugacity of the chemicals in the top soil/snow (Cabrerizo et al, 2009, 2013a, 2013b). Air-soil/snow equilibrium is ensured by operating at a low sampling flow rate of 8-10 $\mathrm{L} \mathrm{min}^{-1}$, thus the air flowing below a stainlesssteel plate of $1 \mathrm{~m}^{2}$ located $3 \mathrm{~cm}$ above the soil/snow surface equilibrates with the underlying surface as demonstrated for soil surfaces (Cabrerizo et al, 2009). The application of this sampler to snow surface has also provided consistent results (Cabrerizo et al, 2013a, 2013b). In addition, a reference air sample collected at $1.5 \mathrm{~m}$ height allows the monitoring of contaminant air concentrations in the lower atmosphere. in both samples, the air passes through pre-combusted glass fiber filters (GF/F,
$47 \mathrm{~mm}$ diameter) to remove particulate matter and $10 \times 2 \mathrm{~cm}$ precleaned polyurethane foam plug (PUFs), in which the gas phase compounds are retained. The average air volume sampled was $67 \pm$ $15 \mathrm{~m}^{3}$. Sampling events, dates and air temperatures are given in the Supplementary Information (Table S1,SI).

The ground at the sampling site was frozen and/or covered by ice or snow between October 2013 and April 2014. Eight soil samples were taken after each soil fugacity samplings between May and September 2013 and between May and July 2014, by gently collecting the soil surface layer (top 0.5-1 cm). After sampling, all samples were stored in freezers at $-20^{\circ} \mathrm{C}$ until analysis. Soil was not sampled during the snow covered period, from November 2013 to April 2014.

\subsection{Analytical procedures}

All concentrations were determined from single samples. All samples were Soxhlet extracted with acetone:hexane (3:1, v:v) for $24 \mathrm{~h}$ and fractionated as described elsewhere (Cabrerizo et al, 2009, 2013a). Hexachloro benzene (HCB), hexachlorocyclohexane isomers $(\alpha-\mathrm{HCH}, \beta-\mathrm{HCH}, \gamma-\mathrm{HCH}, \delta-\mathrm{HCH})$ and $\mathrm{PCB}$ congeners were analysed by a gas chromatograph equipped with a $\mu$-electron capture detector (GC- $\mu-E C D$, Agilent Technologies, model $7890 \mathrm{~N}$ ) with a $60 \mathrm{~m}$ $(0.25 \mathrm{~mm}$ i.d. $\times 0.25 \mu \mathrm{m}$ film thickness) DB-5 capillary column. The instrument was operated in splitless mode (closed for $1.5 \mathrm{~min}$ ) and the oven temperature program started at $90^{\circ} \mathrm{C}$ to $190^{\circ} \mathrm{C}$ at $15^{\circ} \mathrm{C} / \mathrm{min}$, then to $203^{\circ} \mathrm{C}$ at $3{ }^{\circ} \mathrm{C} / \mathrm{min}$ (held for $5 \mathrm{~min}$ ), to $290^{\circ} \mathrm{C}$ at $3{ }^{\circ} \mathrm{C} / \mathrm{min}$, and finally to $310^{\circ} \mathrm{C}$ at $5^{\circ} \mathrm{C} / \mathrm{min}$ (held for $10 \mathrm{~min}$ ). Injector and detector temperatures were 280 and $320^{\circ} \mathrm{C}$ respectively. Helium and nitrogen were used as carrier $(1.5 \mathrm{~mL} / \mathrm{min})$ and makeup $(60 \mathrm{~mL} / \mathrm{min})$ gases, respectively, and $2 \mu$ of sample were injected. The following PCB congeners were analysed: tri-PCB 18, 17, 31, 28; tetra-PCB 52, 49, 44, 74, 70; penta-PCB 95, 99/101, 87, 118; hexa-PCB 110, 151, 149, 153, 132, 105 , 138, 158, 128, 169; hepta-PCB 187, 183, 177, 171, 156, 180, 191,170; octa-PCB 201/199, 195, 194, 205; nona-PCB 206, 208 ; deca-PCB 209.

PAHs were analysed by a gas chromatograph coupled to a mass spectrometer (GC/MS). Samples were injected in an Agilent 6890 GC System with a $30 \mathrm{~m}(0.25 \mathrm{~mm}$ i.d. $\times 0.25 \mu \mathrm{m}$ film thickness $)$ capillary column (HP-5MS) coupled with a mass spectrometer Agilent 5973 (GS-MS) operating in selected ion monitoring (SIM) and electron impact mode $(71 \mathrm{eV})$. The oven temperature was increased to $90^{\circ} \mathrm{C}$ (held for $1 \mathrm{~min}$ ), then increased to $175{ }^{\circ} \mathrm{C}$ at $6{ }^{\circ} \mathrm{C} / \mathrm{min}$ (held for $4 \mathrm{~min}$ ), increased to $235^{\circ} \mathrm{C}$ at $3{ }^{\circ} \mathrm{C} / \mathrm{min}$, increased to $300^{\circ} \mathrm{C}$ at $8{ }^{\circ} \mathrm{C} /$ min (held for $8 \mathrm{~min}$ ), and finally to $315^{\circ} \mathrm{C}$ at $3{ }^{\circ} \mathrm{C} / \mathrm{min}$ (held for $8 \mathrm{~min}$ ). Injector and transfer line temperatures were $280^{\circ} \mathrm{C}$ and 300 "C, respectively, and $2 \mu$ of sample were injected.

The following parent PAHs and alkyl homo logues were analysed ( 53 ind ividual PAHs): acenaphthylene (Act), acen aphthene (Ace), fluorene (Fu), phenanthrene (Phe), anthracene (Ant), dibenzothiophene (DBT), fluoranthene (Flt), pyrene (Pyr), benzo[a]anthracene (B|a|ant), chrysene ( $\mathrm{Cry}$ ), benzo[b]fluoranthene ( $\mathrm{B}[\mathrm{b}] \mathrm{f})$, benzo $[k]$ fluoranthene (B $[k] f)$, benzo[e]pyrene (B|e]pyr), benzo[a]pyrene (B|a]pyr), perylene (Pery), dibenzo| $a, h]$ anthracene (Dib $[a, h \mid a n t)$, benzo $[\mathrm{g}, h, i]$ perylene (B [ $g$ h,ilpery), indend $1,2,3-c d \mid$ pyrene $(\operatorname{In}[1,2,3-c d]$ pyr), benzo[g,h,i]fluoranthene (B $[g, h, i] \mathrm{f})$, methylphenanthrenes (ZMP, sum of 4 isomers), dimethylphenanthrenes (EDMPD, sum of 7 isomers). methyldibenzothiophenes (¿MDBT, sum of 3 isomers), dimethyldibenzothiophenes (EDMDBT, sum of 5 isomers),

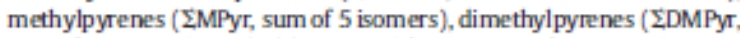
sum of 8 isomers), methylchrysenes (¿MCry, sum of 2 isomers).

\subsection{Quadity assurance/quality control}

To minimize contamination during analysis, PUF plugs were initially pre-cleaned by Soxhlet extraction ( with acetone/hexane (3:1, v:v), $24 \mathrm{~h}$ ) before sampling. Filters were individual hy wrapped in aluminium foils and pre-combusted at $4500^{\circ} \mathrm{C}$ for $4 \mathrm{~h}$. 
Procedural and/or field blanks (4 and 4, respectively) were analysed with each batch of 4-5 PUF samples to monitor potential contamination during sampling and extraction. Soil potential contamination was monitored by 3 procedural blanks. Field blanks consisted of PUFs that had traveled and been handled together with the field samples. Procedural blanks were the result of analytical procedures without PUF. The limits of quantification (LOQs) were defined as the mean concentration of field or procedural blanks (using always the more restrictive of the two) plus three times the standard deviation of the blank response. For the analytes which were not found in procedural blanks, LOQs were derived from the lowest standard in the calibration curve.

To monitor recoveries, samples were spiked prior to extraction with PCB congeners 65 and 200 and deuterated PAH standards (acenaphthene-d10, phenanthrene-d10, cry sene-d12 and perylened12) which were used as surrogate standards. The quantification followed the internal standard procedure, using anthracene-d10, pyrene-d 10, p-terphenyl-d 14, and benzo[b]fluoranthene-d12 for PAHs and $P C B$ congsners 30 and 142 . Average recoveries ranged from $58 \pm$ $20 \%$ for acenaphthene-d 10 to $110 \pm 22 \%$ for crysene-d 12 for PUF samples, and from $58 \pm 16 \%$ for acenaphthene-d 10 to $110 \pm 11 \%$ for perylene-d 12 for soil samples (Table S2, SI). Recoveries of PCB surrogates ranged from $70 \pm 28 \%$ to $80 \pm 29 \%$ for PUF samples, and from $74 \pm 22 \% 81 \pm 10 \%$ for soil samples (Table S2, SI). One sample was discarded for PAH results due to kw PAH surrogate recoveries ( $<10 \%)$.

\section{Results and discussion}

\subsection{Atmospheric concentrations}

Results from the air samples collected at $1.5 \mathrm{~m}$ height revealed ambient air concentrations for $\sum_{53} \mathrm{PAHs}, \sum_{40} \mathrm{PCB}$ and $\sum_{5}{ }_{5} \mathrm{CP}$ s in the ranges $2.6-34 \mathrm{ng} \mathrm{m}^{-3}, 64-460 \mathrm{pg} \mathrm{m}^{-3}$ and $26-270 \mathrm{pg} \mathrm{m}^{-3}$, respectively (Fig. 1, Tables S3-4, SI). These atmospheric levels are higher than in other rural and remote areas of Europe (Shahpoury et al. 2015; Nizzetto et al., 2010, 2017; Anttila et al., 2016; Halse et al. 2011; Hung et al., 2010,2016), yet below the average concentrations of northem European urban areas (Li et al., 2009). Although the sampling site was based in an urban coastal area, these low SVOC atmospheric concentrations are consistent with Tromsø's bw population density (around 3000 persons $\mathrm{km}^{-2}$ ).

The PCB and PAH concentration profiles in the gas phase were dominated by the lower molecular weight (MW) compounds with the higher MW compounds frequently below LOQ (Tables S4-5, Figs. S1-2, SI), consistent with previous studies (Shahpoury et al., 2015; Nizzetto et al., 2010, 2017; Anttila et al., 2016; Halse et al., 2011). PAHs with 3 aromatic rings contributed on average to $71 \pm$ $15 \%$ of $\sum_{53}$ PAHs, with Phe as the main contributor $(29 \pm 7.9 \%)$ to $\sum_{53}$ PAHs air concentrations. $\sum$ Hexa-PCBs and $\sum$ Tetra-PCBs were the main contributors to $\sum_{40} \mathrm{PCBs}$ ( $32 \pm 22 \%$ and $32 \pm 17 \%$, respectively). $\sum_{5} \mathrm{OCP}$ composition was dominated by $\mathrm{HCB}(84 \pm 8.9 \%)$, with $\mathrm{HCB}$ air concentrations ranging from $\angle \mathrm{LOD}$ to $270 \mathrm{pg} \mathrm{m}^{-3}$, and $\Sigma_{4} \mathrm{HCH}$ air concentrations from 2.6 to $42 \mathrm{pg} \mathrm{m}^{-3}$.

Generally, atmospheric concentrations showed a marked seasonal variability with highest concentrations for most of the targeted SVOCs during the warmest months (July and August 2013), and minimum concentrations during the winter (November 2013 to February 2014) (Fig. 1). The temperature dependent seasonality in atmospheric concentrations was supported by significant correlations of the gas phase concentrations with the inverse of air temperature for $\sum_{40} \mathrm{PCBs}\left(\mathrm{r}_{\mathrm{s}}^{2}=\right.$ $0.30, p<0.05)$ and $\sum_{4} \mathrm{HCHs}\left(\mathrm{r}_{\mathrm{s}}^{2}=0.48, p<0.01\right)$, as well individual $\mathrm{HCHs}, \mathrm{PCB}$ congeners and some PAHs (Fig 2, Table S5, S). This is consis. tent with previous studies reporting temperature dependent atmospheric concentrations of semivolatile POPs (Wania et al., 1998; Brunciak et al., 2001; Cortes et al., 1998; Castro-jiménez et al, 2009), and constitutes evidence of a dominant role of surface-air exchange as a driver of the atmospheric occurrence of POPs (Wania et al., 1998;

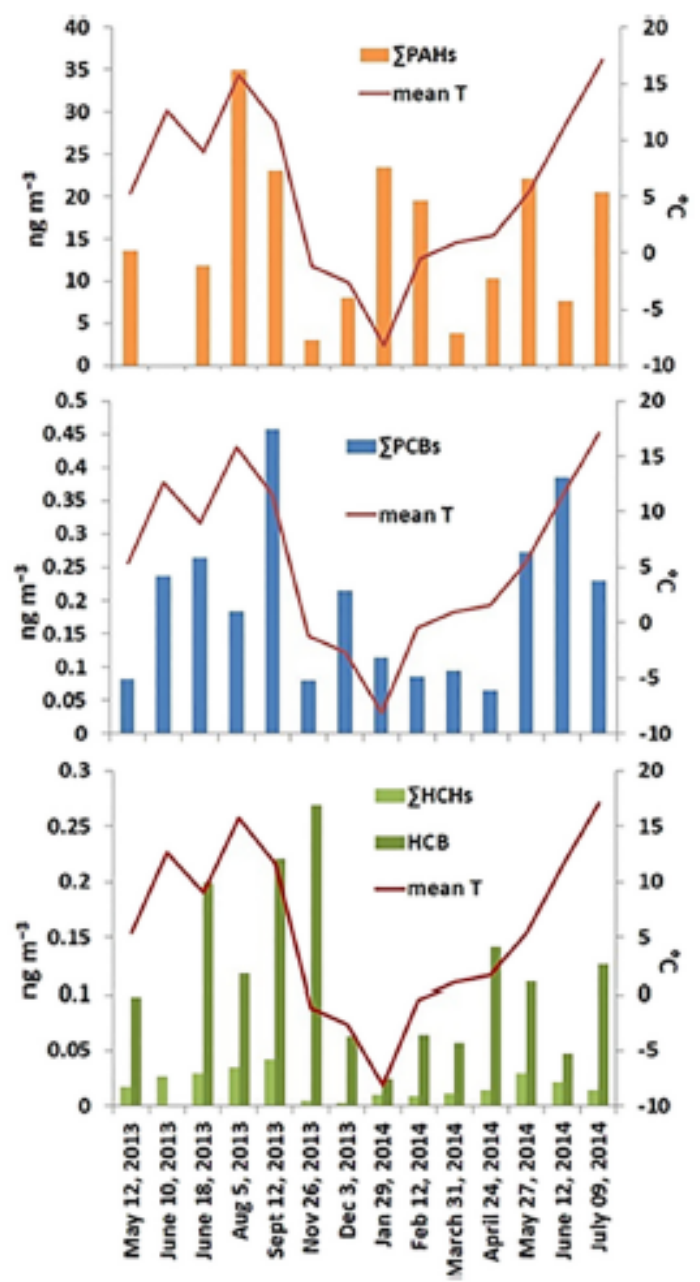

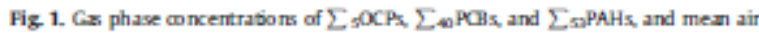
temperature ("C), Salwa snow avered form November 2013 to April2014.

Cabrerizo et al, 2013a, 2013b, 2014), probably from proximate land regions. However, gas-particle SVOCs partitioning is also driven by temperature (Finizio et al., 1997), which could contribute to higher gas phase concentrations at higher temperatures. In contrast, isolated arctic areas at similar or even lower latitudes have been shown to present a lack of temperature dependent atmospheric concentrations which may reflect bng range transport (Oehme et al., 1996; Stern et al. 1997; Wania et al., 1998), especially over oceanic regions were air and water are often at dis-equilibrium. The concentrations of $\sum \mathrm{MePAHs}$ and some of the analysed PAHs (DBT, LMDBT, EMP and LDMPD) were also significantly correlated with the inverse of air temperature (Fig. 2, Table S5, SI), however, this correlation was not significant for $\sum_{53} \mathrm{PAH} s$ as most of the individual PAHs did not show a clear seasonality pattern. This lack of temperature dependence of PAHs in the gas phase is consistent with reports at temperate urban regions where local anthropogenic sources, such as vehicular traffic or domestic heating, have a strong influence on $\mathrm{PAH}$ atmospheric concentrations during the winter (Gigliotti et aL, 2000). The observed high $\sum_{53} \mathrm{PAHs}$ atmospheric concentrations from December to February are likely related to an increase of wood-based household heating during winter in this region (Launhardt et aL, 1998; Solli et al., 2009). 

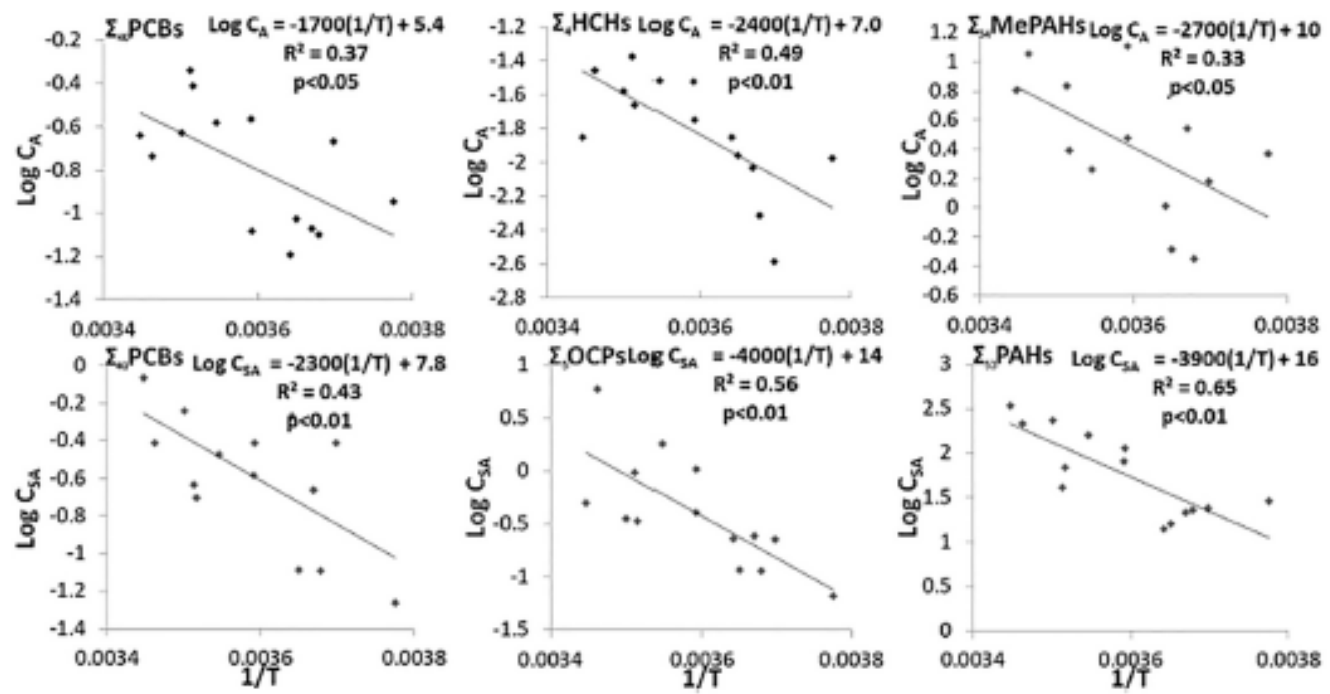

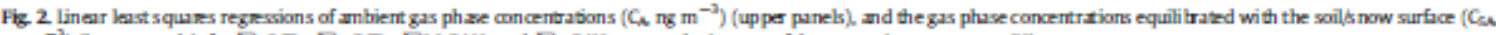

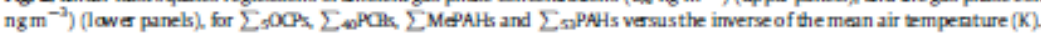

72-Hour air mass back-trajectories were also evaluated every $12 \mathrm{~h}$ for each sampling event using the US National Atmospheric and Oceanic Administration (NOM) Hysplit model (Draxler, 2010) (Fig. S3, SI). Due to the long duration of each sampling event, samples integrate the concentrations of air masees with diverse back-trajectories, in some cases from opposite directions. Higher concentrations air samples did not coincide with a dominance of southern (mainland) back-trajectories nor lower concentrations with northern air masses. This is consistent with a larger relevance of local sources and remobilization processes driving the atmospheric concentrations in Tromss.

\subsection{Occurrence in surface soils}

Concentrations of $\sum_{53} \mathrm{PAHs}, \sum_{40} \mathrm{PCBs}$ and $\sum_{5} \mathrm{OCP}$ in soils ranged from 67 to $290 \mathrm{ng} \mathrm{g}^{-1}, 0.3$ to $0.95 \mathrm{ng} \mathrm{g}^{-1}$ and 0.67 to $1.5 \mathrm{ng} \mathrm{g}^{-1}$, respectively (Tables S6-7, SI). PCB composition was dominated by $\sum$ HexaPCBs $(40 \pm 2.3 \%)$ to $\sum_{40} P C B s$, followed by $\Sigma$ Penta- and $\Sigma$ Hepta-PCBs, while the lighter $\Sigma$ Tri-PCBs had a small contribution to $\sum_{40} \mathrm{PCBs}$ ( 3.5 $\pm 3.9 \%$ ) (Fig. S2, SI). PAH profile was also dominated by the 4 aromatic rings parent- and methylated-hydrocarbons (Flu, Pyr, Cry, B[a]ant, ¿MPyr, ¿DMPyr and ¿MCry), which accounted for $46 \pm 3.4 \%$ of $\sum_{53} \mathrm{PAHs}$ (Fig. S1, SI). These concentrations and profiles are comparable to results from previous studies at high latitude or temperate European regions (Zhuet al., 2015; Meijer et al., 2002; Ma et al., 2008; Nam et al, 2008; Cabrerizo et al., 2011a, 2011b, 2011 c; Bosch et al., 2015; Holoubek et al., 2009; Schuster et al., 2011). HCB was the main contributor ( $96 \pm 3.9 \%$ ) to $\sum_{5} O C P s$, with soil concentrations ranging from 061 to $1.5 \mathrm{ng} \mathrm{g}^{-1}$

SOM is generally regarded as a key factor goveming the soil reservoir capacity (Dalla Valle et al., 2005) and soil-air partitioning and exchange for hydrophobic pollutants (Hamer et al., 2001; Cabrerizo et al, 2011a, 2011b, 2011 c, 2013a). Correlations between POPs concentrations in soil and SOM (or the fraction of organic carbon (foc)) have been reported for several biomes including high latitude polar regions (Meijer et al., 2003; Ribes et al., 2003; Cabrerizo et al., 2012; Schuster et al., 2011). In this study, however, no significant correlations were found between foc and the concentrations in soil of the target compounds. This lack of correlation does not undermine the role of SOM in air-soil partitioning but rather reflects the limited foc variability among samples, ranging from 6.5 to $10 \%$, since all samples were collected at the same sampling site, and thus were not covering a spatial range as in other studies. Furthermore, SOM quality and structural composition also play an important role in air-soil partitioning (Mader et al., 1997; Valsaraj et al., 1999), even though the chemical composition of OC was not evaluated in these samples. Average air temperatures for the soil sampling periods ranged from -5.4 to $17^{\circ} \mathrm{C}$ Concentrations of PAHs, PCBs and OCPs in soils showed no clear seasonality and did not present significant correlations with air temperature for any of the target compounds, reflecting the relevance of soils as a reservoir of SVOCs, due to its fugacity capacity hundreds of times higher than in the atmosphere (Dalla Valle et al, 2005).

\subsection{Soil/snow-air partitioning of SVOCs}

The profiles of gas phase concentrations equilibrated with the soil or snow surface $\left(C_{S A}\right)$, directly proportional to the soil or snow fugacity and obtained with the fugacity sampler, were similar to those found in ambient air $\left(C_{A}\right)$, with an even lower contribution of high MW compounds (Figs. S1 -2, SI). PAHs with 3 aromatic rings contributed on average to $90 \pm 6.9 \%$ of $\sum_{53}$ PAHs and $\sum$ Tetra-PCBs were the main contributors to $\sum_{40} \mathrm{PCBs}(47 \pm 17 \%) . \mathrm{C}_{S M}$ concentrations were generally higher than $\mathrm{C}_{A}$ (Fig. S5, Tables S8-9, SI) and showed stronger seasonal patterns with higher $S V O C$ concentrations during warmer months. Furthermore, $\mathrm{C}_{5 \wedge}$ presented significant correlations with air temperature for $\sum_{53} \mathrm{PAHs}, \sum_{40} \mathrm{PCBs}$ and $\sum_{5} \mathrm{OCPs}$ (Fig. 2), consistent with the role of temperature as a primary control on the soil-air and snow-air partitioning and exchange of SVOCs. Information on the statistically significant $\mathrm{C}_{S \Lambda}$ correlations with air temperature for 17 of the target compounds are compiled in Table $S 10$ (SI). Unlike $C_{A}, C_{S A}$ seasonality patterns were likely unaffected by local PAHs sources due to its higher concentrations

Soil-air partition coefficients $\left(\mathrm{K}_{\mathrm{SA}}\right)$ were calculated as:

$K_{S A}=\frac{C_{S}}{C_{S A}}=\frac{f_{O C}}{\rho_{\propto C T}}\left(\frac{\gamma_{\propto c \tau} M W_{\alpha q}}{\gamma_{\propto C} M W}\right) K_{\alpha A}$

where $\mathrm{C}_{\mathrm{S}}\left(\mathrm{ng} \mathrm{kg}_{\mathrm{w}}^{-1}\right)$ is the individual SVOC concentration in surface soil, and $\mathrm{C}_{s \Lambda}$ ( $\mathrm{ng} \mathrm{dm}{ }^{-3}$ ) is the gas phase concentration that has been 
equilibrated with the soil or snow surface (TablesS8-9, SI) as measured using the soil fugacity sampler. $\mathrm{K}_{\mathrm{SA}}\left(\mathrm{L} \mathrm{kg}^{-1}\right)$ has been previously modelled as a function of the octanol air partition coefficient $\left(K_{0 n}\right)$. where $\gamma_{\alpha c}$ and $\gamma_{\alpha c}$ are the activity coefficients of SVOCs in octanol and organic carbon, respectively, MW $\mathrm{MCr}\left(\mathrm{g} \mathrm{mol}^{-1}\right)$ and $\mathrm{MW}_{\odot \mathrm{C}}$ $\left(\mathrm{g} \mathrm{mol}^{-1}\right.$ ) are the molecular weight of octanol and organic carbon, respectively, $\rho_{0 c}$ is the octanol density, and $f_{\alpha}$ is the fraction organic carbon of the soil (Finizio et al., 1997). Kon was temperature corrected as reported elsewhere (Pamis et al., 2015; Shoeib and Harner, 2002;

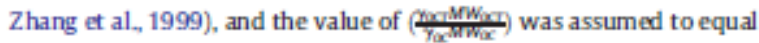
unity (Cabrerizo et al, 2009).

Least squares linear regressions of $\log K_{S A}$ versus $\log K_{\text {OA }}$ showed statistically significant correlations for PAHs and PCBs (Fig. 3) explaining between 20 and $46 \%$ of the variability. It is noteworthy that these $\mathrm{K}_{\mathrm{SA}}$ have been estimated from measurements of the fugacity in soil and not from models. These results are consistent with previous studies and support the role of SOM in soil-air partitioning of hydrophobic compounds (Finizio et al., 1997; Cabrerizo et al., 2011a, 2011 b, 2011c). The slopes of $L_{\log } \mathrm{K}_{\mathrm{SA}}$ versus $\log \mathrm{K}_{\mathrm{an}}$ differed considerably from 1 (Fig. 3). Additionally, there were large differences between the value of $\log \mathrm{K}_{\mathrm{SA}}$ and $\mathrm{Log} \mathrm{K}_{\mathrm{O}}$ f for some compounds, which undermines the use of $\mathrm{K}_{\mathrm{On}}$ as a singular air-soil partitioning pred ictor. Furthermore, OCPs linear regression presented a negative slope since HCB presented higher $\mathrm{K}_{\mathrm{SA}}$ values than $\mathrm{HCHs}$ (Fig. 3). However, the regression was not statistically significant for $\mathrm{HCB}$ or $\sum_{4} \mathrm{HCH}$ considered separately (Fig. SA, SI).

\subsection{Fugacity in soils, snow and air}

The fugacities of the SVOC in air $\left(\mathrm{f}_{\mathrm{a}}, \mathrm{Pa}\right)$ and in the snow or soil ( $\mathrm{f}_{\mathrm{s}}$ $\mathrm{Pa}$ ) were calculated by:

$$
\begin{aligned}
& f_{a}=10^{-9} C_{A} R T / M W \\
& f_{s}=10^{-9} C_{S A} R T / M W
\end{aligned}
$$

where $\mathrm{R}$ is the gas constant $\left(8.314 \mathrm{~Pa} \mathrm{~m}^{3} \mathrm{~mol}^{-1} \mathrm{~K}^{-1}\right.$ ), $\mathrm{T}$ is the temperature $(\mathrm{K})$, and $\mathrm{MW}$ is the chemical molecular weight $\left(\mathrm{g} \mathrm{mol}^{-1}\right.$ )

Least squares linear regressions of $\log f_{\mathrm{s}}$ versus $\log f_{\mathrm{a}}$ (Fig. 4) also showed statistically significant correlations for PAHs, OCPs and PCBs with $R^{2}$ values of $0.63,0.56$ and 0.18 , respectively. In general, $f_{a}$ values were lower than $\mathrm{f}_{\mathrm{s},}$, which is reflected in linear regressions that presented slopes below 1 . This is consistent with previous fugacity based studies on background temperate areas (Cabrerizo et al, 2013a) and Antarctica (Cabrerizo et al, 2013b), and further supports the relevance of secondary emissions as drivers of the atmospheric concentrations and points to the close coupling between air and soils/snow surface in terms of SVOC occurrence.

The comparison of $f_{a}$ and $f_{a}$ values allows determining the direction of soil/snow - air exchanges. $\mathrm{f}_{J} / \mathrm{f}_{\mathrm{A}}$ ratios higher than 1 reflect a net volatilization of a chemical. In return, $\mathrm{f}_{N} / \mathrm{f}_{\mathrm{a}}$ ratios lower than 1 indicate the net deposition of the chemical The effect of the uncertainty in the measurements has been previously quantified (Cabrerizo et al., 2011a, $2011 b$ ), and air-soil/snow equilibrium is considered for $\operatorname{Ln} \mathrm{f}_{s} / f_{a}$ values between -1.2 and 0.53 .

$\mathrm{f}_{\mathrm{j}} / \mathrm{f}_{2}$ ratios showed a large variability for ind ividual $\mathrm{PAHs}, \mathrm{PCBs}$ and OCPs depending on the compound hydrophobicity (Tables S11-12, SI, Fig. 5) and ambient temperature (Fig. 6). Statistically significant least squares linear regressions of $\mathrm{Ln}_{\mathrm{s}} / \mathrm{f}_{\mathrm{A}}$ versus $\log \mathrm{K}_{\mathrm{OA}}$ showed that in general the most hydrophobic compounds were closer to equilibrium or showed a net deposition, regardless of the season (Fig. 5). However, all target compounds with $L$ g $\mathrm{K}_{\mathrm{OA}}$ lower than 10 showed a net volatilization during part of the year, especially the warmer months. This is consistent with previous studies and supports the relevance of soil volatilization as a source of lighter SVOCs (Cabrerizo et al., 2011a, 201 1b,
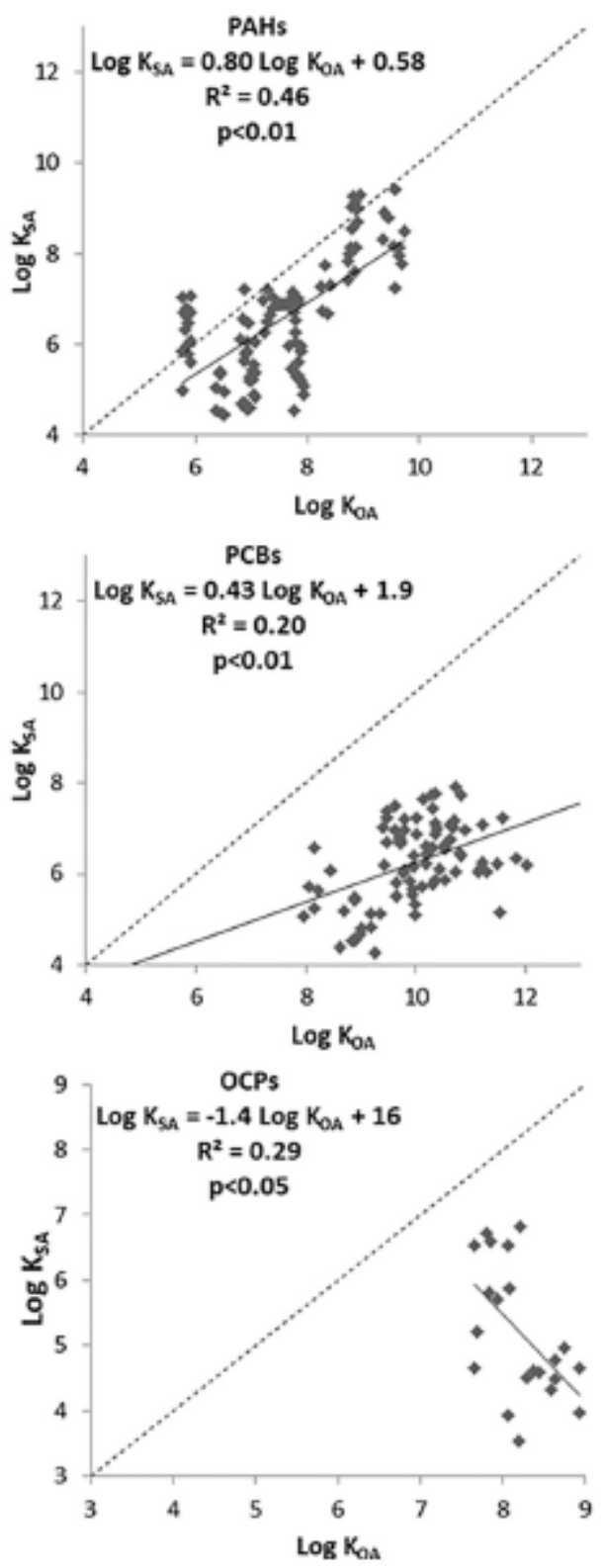

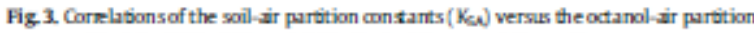

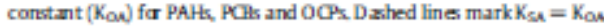

2011c, 2013a). However, In $f_{s} f_{a}$ showed poor correlations with Log $\mathrm{K}_{\mathrm{O}}$, explaining only 5 and $11 \%$ of variability for $\mathrm{PAH} s$ and $\mathrm{PCBs}$, respectively. $O C_{5} \mathrm{Ln} \mathrm{f}_{/} / \mathrm{f}_{2}$ ratios presented no significant correlation with Log $\mathrm{K}_{\mathrm{OA}}$ (Fig S6, Sl), although for its main contributor, $\mathrm{HCB}$, a linear regession was statistically significant and explained $42 \%$ of variation due to the influence of temperature on $\mathrm{K}_{\mathrm{on}}$ (Fig. 5).

PAHsaverage $\ln \mathrm{f}_{-} \mathrm{f}_{\mathrm{A}}$ ratios were between -12 and 0.53 (near equilibrium) from January to March, and higher than 0.53 (volatilization) during the rest of the year (Table S11, SI). In general, the maximum individual PAH In $\mathrm{f}_{\mathrm{s}} \mathrm{f}_{2}$ ratios were detected during June and July of 2013 and 2014 (Table S11, SI). This is consistent with a higher relevance of soils as a source of PAHs, HCB and other SVOCs during warm conditions, 

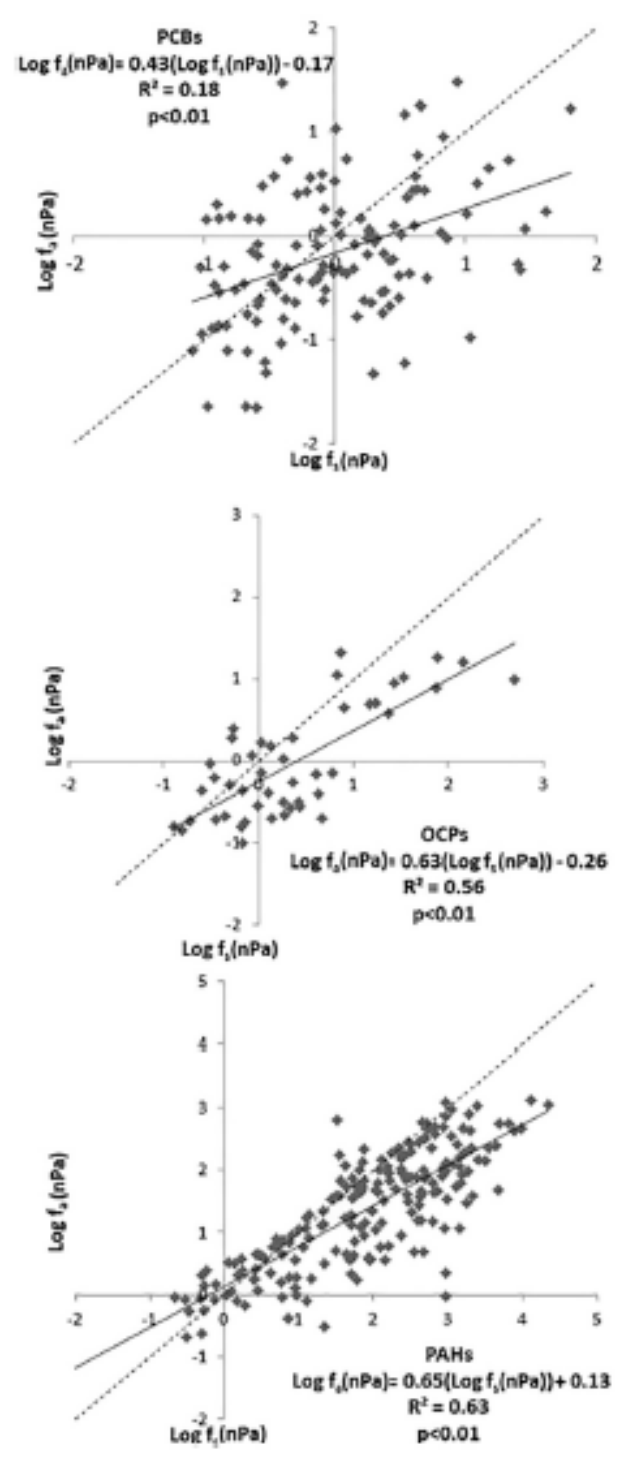

Fig. 4. Fugacityin ar ( $\mathrm{f}_{2}$ ) versus fugacity in soil ( $\left.\mathrm{f}_{2}\right)$ for $\mathrm{PCBs}, \mathrm{OCP}$ and $\mathrm{PAH}$.

contributing to the temperature dependent gas phase concentrations (Fig. 2), through a close air-soil coupling of concentrations (Fig. 4). The low ratios observed in winter reflect the high sorbing capacity of snow for SVOCs, thus lowering the escaping tendency of PAHs from the surface. The $\mathrm{Ln} \mathrm{f}_{-} \mathrm{f}_{\mathrm{a}}$ ratios for HCB, Phe, Ant, Flt and Cry, were significantly correlated with temperature (Fig. 6, Table S13, SI). Conversely, the lack of correlation of $\mathrm{Ln}_{s} / \mathrm{f}_{a}$ ratios for $\mathrm{PCBs}$ and $\mathrm{HCH}$ s with temperature can be explained by their simult aneous $\mathrm{C}_{\mathrm{SA}}$ and $\mathrm{C}_{\mathrm{A}}$ correlations with temperature and remarkable seasconal patterns, which induces a lack of seasonality in $\mathrm{f}_{s} / \mathrm{f}_{a}$ ratios for these compounds

\section{Conclusions}

In the present study, the role of temperature in the ambient concentrations and the soil/snow-air partitioning of SVOCs was evaluated for a large number of organic chemicals representing a wide range of physical-chemical properties. On the one hand, the atmospheric
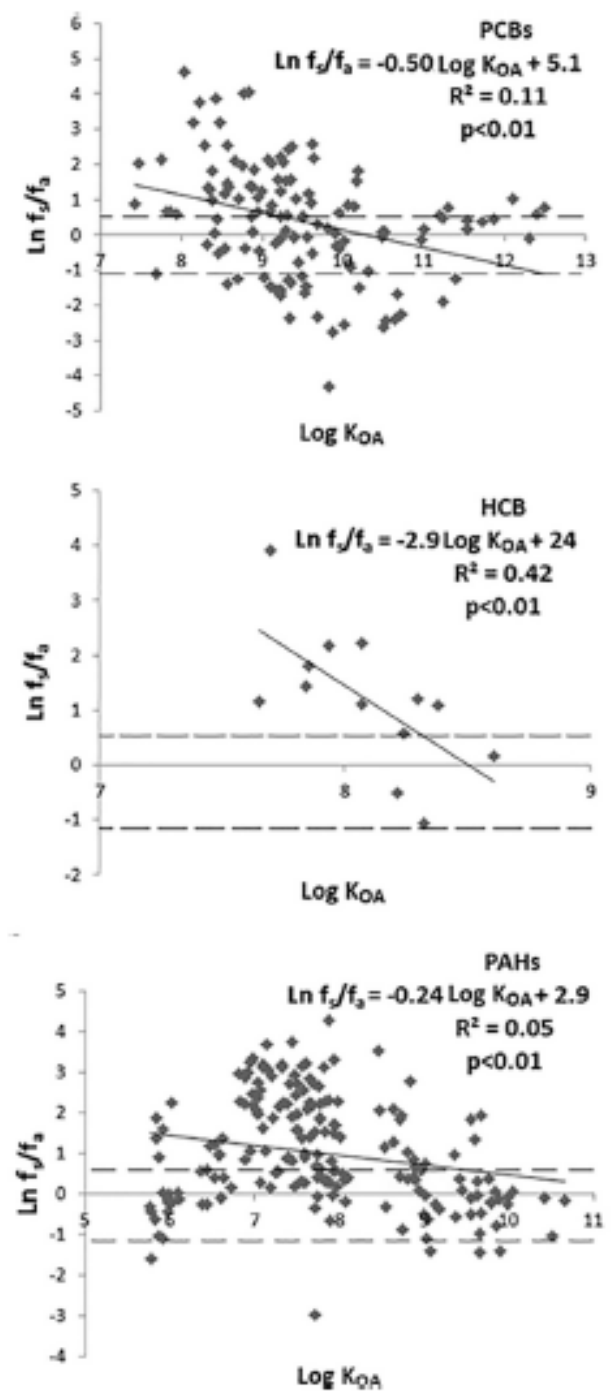

Fig S. Variation of the soil-air fugacity ratio $\left(\ln \mathrm{f}_{\mathrm{N}} / \mathrm{f}_{\mathrm{a}}\right)$ versus the octanol-air partition coefficient ( $K_{\text {oul }}$. The horiontal dashed lines mark rabos -1.2 and 0.53 , interval for airsurfice equilibium

concentrations $\left(C_{N}\right)$ and the concentrations in the gas phase equilibrated with the surface soil/snow $\left(\mathrm{C}_{S \mathrm{~S}}\right)$ for $\mathrm{PCB}$ s and $\mathrm{HCH}$ s showed a clear seasonality correlated with temperature. In addition, soil/snow fugacity was correlated with air fugacity which constitutes evidences of the relevance of soils as dominant bcal sources of these SVOCs in the atmosphere, except for the higher MW PCBs. The more hydrophobic POPs were close to equilibrium or showed a net diffusive deposition. A close coupling between the atmospheric and soil/snow compartments for $\mathrm{PCBs}$ and $\mathrm{HCH}$ in this arctic site has been confirmed during the study period as reflected by their $\mathrm{f} / \mathrm{f}$, ratios (close to equilibrium conditions with a lack of a clear seasonality). On the other hand, PAHs and $\mathrm{HCB}$ showed a clear seasonality in $\mathrm{f}_{,} \mathrm{f}_{\mathrm{a}}$ ratios with equilibrium conditions during winter months and net volatilization during the rest of the year, which constitutes evidence of the relevance of soils as secondary sources and highlights the role of temperature on the soil/snow-air exchange of SVOCs. 


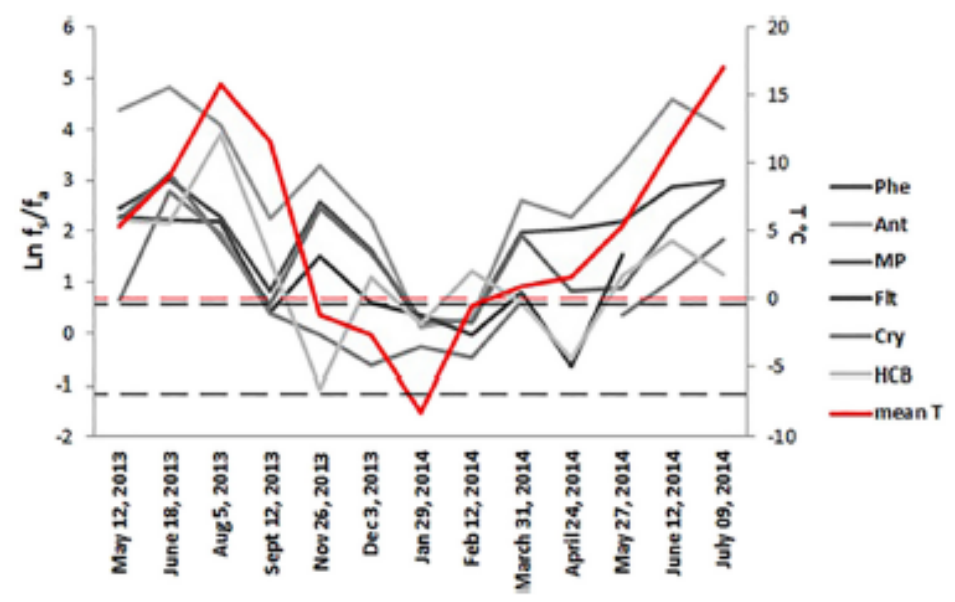

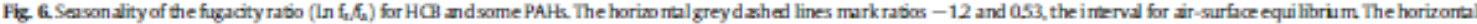

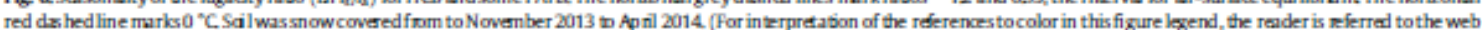
version of this arbicle)

\section{Acknowledgements}

This work has been financed by the Spanish Ministry of Economy and Competitiveness (REMARCA, CTM2012-34673). Dr. Ingjerd S. Krogseth is kindly acknowledged for assistance during sampling and comments on the manuscript. P.C acknowledges a FPl fellowship from the Spanish Economy and Competiveness Ministry.

\section{Appendix A.Supplementary data}

Supplementary data to this article can be found online at https://da. org/10.1016/.jscitotenv.2018.04.330.

\section{References}

Anttiln P, Arorström-lundén, E., Hansson, K, Hakola H., Vetteriuk, M, 2016. Assessment: of the spatial and tmmoral distribution of persistert arganic pollutants (POPs) in the of the spatial and temporal distribution of persistz-

Bosch, C, Andersson, A, Krusi, M., Bandh, C, Hovarkovi, L, NGinovi, L, Knowles, T.D. Pancost, R.D. Evers hed, R.P.Custufsson, 0.2015 . Source appo tianment of polycyclic aromatic hydrocarbons in certural European saik with campound-specific triple isotopes $\left(0^{12} \mathrm{C}, \Delta^{14} \mathrm{C}\right.$, and $\left.\mathrm{b}^{2} \mathrm{H}\right)$, Emviron. Sci. Technol. $49,7657-7665$

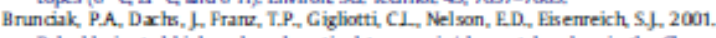
Polychlorinated bipheryls and particulte arganickelemental carbon in the Chesa peake Bay atmosphere. Atmos Envi ron.35,5663-567n.

Currerina, A, Dacks, f, Barceda D, 2009 . Development of a soil fugacity sampler far deter mination of air-soil partitianing of persistent arganic pollutants under field $\omega n$ trolled condibions. Environ.Sai. Fedunol.43 8257-8263.

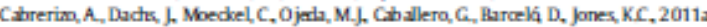
Uthiquitaus net volati izabon of polycyclic aromatic hydrocarbors from soils and $p_{3}$

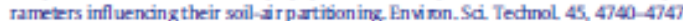

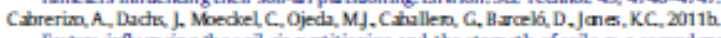
Fxars influescing thesoil-ir partitioning and the strength of soils $x$ a second ary source of polychlorinuted biphenyls to the atmosp here. Emviron. Sd. Technol. 45 , $4785-4792$

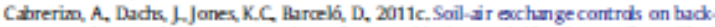
ground atmospheric concentrations of orgmahlarine pesticides. Atmos. Chem. Phys. ground atmosph $12799-12811$.

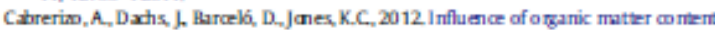
and human xtivibes on the ocrurrence of organic pollutsints in Antractic saik, bi

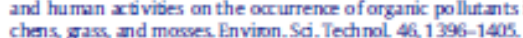

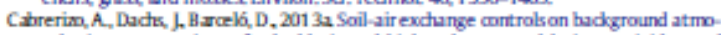
spheric concentrations of polychlorinuted biphenyk, arganochlarine pesticides, and polycyclic aramatic hydrocarbons: a cae study from temperate regions in:

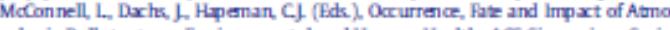
spheric Pollutants on Environmental and Human Health. ACS Simposium Serie: 1149 (Washingan, USA)

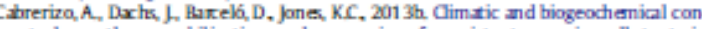
trok on the remobilization and reservairs of persistent arganic pollutants in Amtarctica. Emviran Sa lechnol 47, 4249-4306.
C.ubrerim, A, Galhin Malxyón, C, Del Venta, S, Dxhs, f, 2014 Sources and fite of polycyclic aromatic hyd rocarbons in the Ant:actic and Southem Ocenl atmosphere. Gloh. liogeachen. Cydes 28, 1424-1436

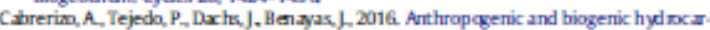
bons in soils and vegetation from the South Shethand klands (Antartica) Sci. Tobl Inviron. $5899,1500-1509$

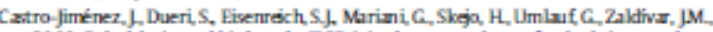
2009 . Palychlarinated biphenyts (PCHs) in the smosphere of sub-al pine narthern Itaiy. Environ. Pollut. 157, 1024-1032.

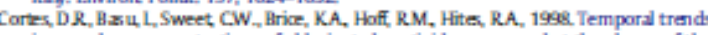
in $\mathrm{ga}$-phaseconcentrations of chlorinated pesticides measured at the shores of the Grex lakes Emviron. Sci Technol. 32, 1920-1927, 1998

Dalla Valle, M, Jurada, E., Dads, J.Sweetman, AY, jane, KC, 2005 . The maximum reser vair capacity of soils for persistent argeric pollutents: implic zions fa global cyding Environ. Pollut 134 (1), 153-164

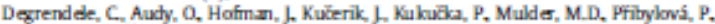

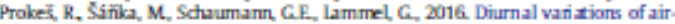
soil exchunge of semivolsile arganic compounds (PAH, PCF, OCP a central Eu ropean reeptor ari. Environ. Sci Technol. 50,4278-4283

Draxler, R.R. 2010 HYSPLT (thybrid single-partide lax rangian integrated trajetory) model acress vin NOAA ARL zudy whiste NOAA Air Resources laboratory. Silver Spring, MD hatp://ready.rlnows.gav/HYSPLIIphp.

Dvorski, A. L anmel G. Holoubek, L, 2009 . Recert trends of pesistert arganic pollutants in ir in central Europe - air moni aring in combin tion wth air mas traje cary sta tistics as a tool to study the effectivity of regional chemical policy Atmos. Emviron 43, $1280-1287$

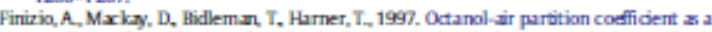
predictor of partibioning of semivolatile o ranic cherricals to aensols. Atmm. Emvi ron. $31,2289-2296$.

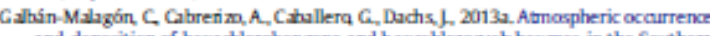
and deposition of hexachlarobenzene and hexachlarocycb hexanes in the Southern ocean and Antarctic perinsuls. Atmen Emviron $80,41-49$

Galhin-Malagoin, C, Del Vertm, S, Cabreriza, A, Dxhs, J. 2013h. Fxtars affecting the at mospheric occurrence and deposition of polychlorinuted biphernyls in the Southern Ocean Atmos. Chem Phys. 11, 12799-12811.

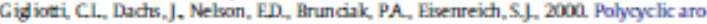
mabic hydrocambons in the New Jersey cosstal atmosphere. Environ. Sci. Technol. 34, $3547-3554$

Halse, AK, Schlahach, M, Eckhurdt S, Sweetman, A, Jane, K.C., Brévik, K, 2011.Spatin varishility of POPs in European badkground air. Atmox Chem Phys. 11, 1549-1564.

H.rne, T, Hidlem.n, TF, Jantunen, L.M, Mxday, D, 2001. Soil-air exch srge modd of persistent pesticides in the Uni ied States cotton belt. Environ Toximl. Chem. 20 1612-1621.

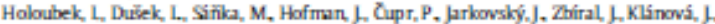
2009 Soil burdens of persistent orgnic pollutents - their levds, fat and risk Part L Vristion of encentrtion ranges $x$ cording tod ifferert soil uses and lastions. En-

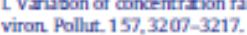

Hung, H, Kallen bom, R, Breivik, K, Su, Y, Bnoström-Lundén, E, Olıfod otir, K, Thorlacius I.M, Leppinen, S, Borsi, R, Slox, H, Mana, S, Patton, C.W., Stern, C, Sverko, E., Fellin P.2010. Atmospheric monitoring of arganic pol lutants in the Arctic under the Arctic Monitoring and Assessmert Progamme (AMA.P); 1993-2006. Sci Tobal Emviron 408. 2854-2873.

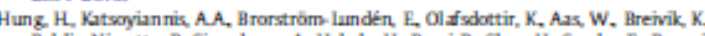

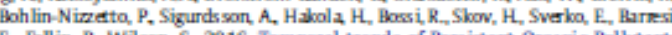
E., Fellin, P., Wilson, S, 2016. Temporal trends of Persistent Organic Pollutants 
(POPs) in arcic air: 20 years of monitaring under the Arctic Moritoring and Assess ment Programme (AMAP), Emviron. Pollut 217, 52-61.

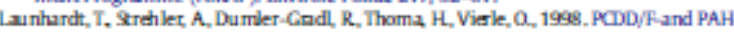
emixsion from houx heating systems Chemos phere 37, 2013-2020

Li, YF., Harner, T, liu, L., Zhang, Z, Ren, NQ. Jia, H., M., J, Sverko, E, 2009 Polychlorinated hiphemyls in glohol air and surface soil; distributions, air -sailen. ch nnge, and fractionution effect. Envion.Sci. Tectnol.44 (8), 2784-2790.

Ma, XD., Wang, Y.J, Na, GS, Lin, ZS, Zhou, CG, Wring, Z, Yao, ZW, 2008. Distribution of organochlorine pestiodes and polychlorinated biphemyls in Ny-Alesund of Arctic arganochlorine pestiodes and poly
area. Chin. I Polar Rer. $20,329-332$.

Madkay, D. Pazerson, S, 1981. Calaulating fugadity. Emviron. Sdi. Technol. 15, 1006-1014

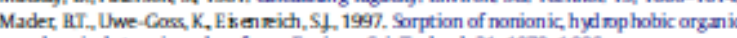
chemicals to mineral surface. Emviron. Sa. Tedunol.31, 1079-1086.

Meijer, SN, Steinnes, E, Ockenden, W.A., janes, K., 2002 Influence of ermironmental variables on the spstis dis tribution of PCHs in Narwerian and UK soils; implicatians for glabal cycling. Emviron. Sci Technol. 36, 2146-2153

Meijer, S.N, Odkender, WA, Sweetman, A, Breivik K, Grimalt, JO, Jones, KC, 2003 , Global distribution and budget of PCHs and HCB in harkground surface soils; implica. tions fa sources and ervironmental processe. Environ. Sci. Tectunol.37, 667-672.

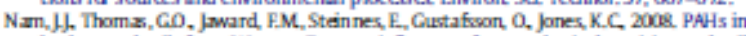
badground soils form Westem Europe influence of Immesp heric deposition and soil argmic mater. Chemosphere 70, 1596-1602

Nizzetta L. Mxieod, M, Barga K, Cabrerim, A, Dacha, J, Di Guarda, A, Chirardella, D, Hansen, K.M. Jarvir, A., lind oth, A, ludwing, H, Manzith, D., Perlinger, JA, Scheringer, M., Schwendenumann, L, semple, K.I., Widk LY, Zhang, G, Jones, K.. 2010. Past, present and future controks on leveds of persistent arganic pollutants in the global enviranment. Enviran.Sci. Technol 44,6526-6531,

Nirsetm, PB, Aas, W., Wryner, NA, 2017. Monitrring of Environmental Contsminumts in Air and Precipitzion, Annual Report 2016. NIIJ R.pport

Oehme, M. Hagen. If. Schlabach. M., 1996 Sexanal changes and relabons between leveds of argmodtlorines in Arctic antient air: first results of an all-year-round monleves of argmochlorines in Arctic mntient air: first results of an all-year-round mon itaring pros

Parnic, JM, Madkay, D, Harner, T, 2015 . Temperature dependence of Henry's law con stants and KOA for simple and heterastom-substituted PAHts by COSMO-RS Atmos Emviran. 11a, 27-35.
Ribes, S, Van Drooge, B, Dacks ,_, Gustafsson, 0 , Grimalt jo, 2003 . Influence of soot carbon on the soil-ir purtitioning of polycyctic arom xic hydrocarbons. Emviron. Sci. Tedunol.37,2675-2680

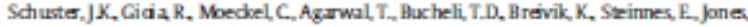
KC. 2011. Has the burden and distribution of PCHs and PHDEs charged in European hadkground soils between 1998 and 2008 ? Implications for sources and processes Emviron Sci. Technol_45, 7291-729?.

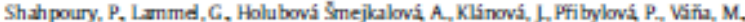

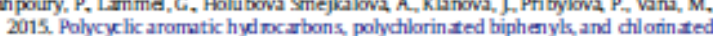
pesticides in background air in central Europe-imestigaing parameters affecting

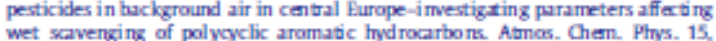
wet savenging

Shoeih, M, Harner, T., 2002 Uking mexsured octanol air partitian coefficients to explain emviro nmental partitioning of ar gnoch larine pesticider Environ. Toxical Chem. $21,984-990$.

Solli, C, Reen $13 x$ M, Strammm, A.H. Hertwich, EC, 2009 Lifecyde assessment of wood based hesting in Norway. Int f. life Cyde Assess $14517-528$

Stem, GA, Hakall C., Harrie, LA, Muir, DCG, Fed lin, P., Rosen berg, B, Rovirsky, FY. Kanonow, EY, Pastuhov, B, 1997. Polychlorinuzed biphemyls in Arctic ir. 1. Temparal and sputisl trends: 1992-1994. Envirn. Sci Technol. 31, 3619-3628

UNEP, 2001.Stodkholm Convertion an Persistert Orgaric Pollut mnt. United Nafions Environment Program, Stadholm

Valsuraj, K.I, Kommabpati R.R, Robertsan, E.D, Constart, WD, 1999 . Partiban canstants and acsaption,desorption hysteresis far vol trile arganic compounds on soil fram 2 Louisiana superfund site Emviron. Monit. Asseas 58, 227-243.

Wamin, F, Hager, JE, lei, YD, Maday, D, 1998. Temperature dependence of atmospheric $m$ ncentrations of semivalatile arganic ampounds. Emviran. Sci. Technol 32. 1013-1021

Zhang X, Scturamm, K.W., Henkelmann, B, Kimm, C, Kaune, A, Kettrup, A, Lu, P., 1999. A method to estimat the octanol-air partibon mefficient of semivd sile organic campound. Anal Chem 71, 3834-3838

Zhu C, Li. Y. Wang. P., Chen, Z, Ren, D., Sebugere, P., Zhang, Q. fing, C., 2015. Palychlarin xed bipheryls (PCEs) and polybrominuzed biphenyl ethers (PBDE) in emviranmental samples from $\mathrm{Ny}$-Alesund and londan ksland, Sval hand, the Arctic Chemosphere $126,40-46$ 